\title{
A SERVQUAL Approach to Identifying the Influences of Service Quality on Leasing Market Segment in the German Financial Sector
}

\begin{abstract}
Purpose - The purpose of this paper is to determine the nature of the relationship between service quality and desired customer behaviours in the leasing market using an appropriate service quality measurement model. We take a step further by recognising the possible differences in influence of service quality in private and corporate customers, and those business dealings with low, medium and high lease values.

Design/methodology/approach - We use deduction method to test the SERVQUAL in the German leasing market and the relationship between customer satisfaction and desired behavioural outcomes. The developed questionnaire is based on the 22 item scale of the SERVQUAL approach. Samples are selected based on convenience sampling.

Findings - We found differences in the levels of inflence by SERVQUAL dimensions on corporate and private customers as well as among those customers with different leasing contract values. From the regression analyses, it is clear that 'assurance' from the leasing company is the most common SERVQUAL dimension that has significant impact on overall service quality perceptions and obtaining customers satisfaction and loyalty (behavioural outcomes).

Originality/Value -We recognised that all financial services are not created equally to meet customer demands. Hence, the customer expectations of service quality from these services will be different. We contributed to the marketing literature by studying customer perceptions of service quality by specifying financing aspects of financial services, i.e. leasing. We further contributed to the literature of SERVQUAL model in financial services by dividing customers into two different types of customers and those with diverse leasing contract values. We found that priorities given on service quality dimensions by them are different. These concepts were never considered in the literature. This also implies that future studies on financial services marketing need to recognise such differences in the research.
\end{abstract}

Keywords

SERVQUAL, Leasing Market, Germany, Service Quality 


\section{Introduction}

'Leasing' is one of the capital financing products offered by financial institutions. According to the standard terms of operating lease, it is a service where the financial institutions act as a leaser and the customer, leasee receives the right to use the leased asset over a specified period of time. The first rental payment would be made when the lease is initiated and the subsequent payments will be made periodically at agreed dates in the future (McConnell and Schallheim, 1983). The leaser would profit from the interests payments included in the periodic instalments made by the leasee. Unlike other types of unsecured financing products that are offered by financial institutions, the leasors retains the ownership title of the asset and even if the leasee were to default, it is simple for the leaser to repossessed the asset, thus, it is one of the least risky financing products. Financing products are the main sources of income and the sustainability of financial institutions depend on them.

Nevertheless, from our analyses of the prior literature, we found that financial and banking services have been defined as a simple concept as all of these services have equally distributed importance for customers and investments. Due to the nature of the risks involved in financing service options, customers' perceived service quality determinants would be different from financial transaction support services. Hence, there is a need to recognise such distinctions in financial service marketing literature. Furthermore, in recent years, service organisations including financial institutions are required to provide high customer service quality in order to be successful in today's highly competitive business environment. It has become more important after the 2008 global financial crisis where the general public lost their trust in the financial system. This crisis has led many scholars to study in the area of risk management, institutional quality and financial regulations. However, limited research has been done from quality management perspective, which will allow us to understand how we can create customer loyalty and trust amid crises by meeting their needs and expectations. In this paper, we choose to study the influence of service quality on customer loyalty in the German leasing service market mainly for three reasons.

According to the 2017 Global Leasing Market Report (Gleeson, 2017), German and UK are the largest and most leasing market in Europe and are the most established in the world after the United States and China. Both UK and Germany accounted for $46.9 \%$ of the European market and $15.6 \%$ of the world market. The Germany's leasing market has a growth of $8.42 \%$ in comparison to 2014 with additional new business volume US\$63.84 billion. Being a mature market means it has strong competition from commercial banks, saving banks, public banks and credit finance companies. Secondly, it is made up largely of small and medium-sized enterprises (SMEs) which have withdrawn from increasing investments in productive physical stocks after the crisis in 2008. Hence, providing high service quality is important for customer retention in such a highly competitive market.

The newly implemented German and European Union (EU) regulations such as increasing capital adequacy, liquidity and securitisation requirements mean escalating the cost of providing leasing services to households, and small and medium sized businesses (SMEs), which are rated at relatively higher risk than corporate customers. In an environment where the financial regulations limiting leasing companies to extend their services to new customers and 
the demand for the facilities from SMEs decreases, these companies need to develop a broad range of comprehensive supports and service quality not only to attract new customers but also to create customer loyalty. Therefore, considering the increased importance of service quality in the leasing market, measuring service quality and understanding its impact on customer satisfaction and other behavioural outcomes, has become a crucial factor for success and profitability in this market sector.

Thus, the objectives of this paper are to determine the nature of the relationship between service quality and desired customer behaviours in the leasing market using an appropriate service quality measurement model. To achieve this research objective, we have developed a structured approach as follows: Firstly, a critical review of the related relevant literature is made in Section 2. Secondly, method of collecting primary survey data and SERVQUAL data descriptions are explained in Section 3. Descriptive data analysis and regression results are discussed in Section 4. Based on the analysis, we provide the discussions of the data along with their implications in Section 5 and the limitations and future research in Section 6.

\section{Literature review}

\subsection{Background of the German leasing market}

In the $21^{\text {st }}$ century, service is the dominant market sector in many countries around the world. The UK was the largest European leasing market in 2015, with new volumes worth $€ 76.9$ billion, followed by Germany (Euro 53.2 billion) and France (Euro 43.6 billion) (Leaseurope, 2015). In Germany, the service sector plays a critical role in the overall economic development. According to the OECD (Organization for Economic Co-operation and Development, 2016), the contribution of the service sector to the country's GDP is $68.9 \%$, followed by production industry $25.7 \%$, construction $4.8 \%$ and agriculture $0.6 \%$. The total assets of banking sector to GDP decreased from $332.9 \%$ in 2010 to $276.8 \%$ in 2014 (EC, 2015). After the 2008 financial crisis, the regulations on the financial sector was tightened. This contributed to the sector's resilience to vulnerabilities and systemic shocks. Similarly, the demand for financing from SMEs, households and corporations has decreased. However, the German financial institutions face the issues of low profitability due to their strong reliance on net interest income. In other words, their main revenue generation stream comes from capital financing products. Despite these negativities in the financial sector, the German leasing market is one of the most mature in the world. As described by Gleeson (2017), different forms of leasing options are dominated in the markets:

“...hire purchase stills plays a secondary role accounting for only $13 \%$ of equipment finance compared to finance leasing of $48 \%$ and operating leasing of 39\%. In 2015 the share of leasing as a financing tool for investment became larger and the equipment and construction industries adopted leasing more frequently. Road vehicles remain the dominant asset class in the German economy (71\%), followed by machinery (13\%) and office equipment and IT systems (6\%). Looking at the equipment leased by type of customer, services, manufacturing and transport segments accounted for more than the $65 \%$ of the total volume..." 
In Germany, the equipment leasing market penetration increased from $13.6 \%$ in 1997 to $16.2 \%$ in 2008. The market was hit by the crisis in 2008 and the penetration rate dropped to $13.9 \%$ in 2009 but it immediately recovered and reached $16.7 \%$ in 2015.

In addition, improving service quality to develop customer loyalty becomes an important agenda for leasing companies due to the consequences rendered by the financial crisis in 2008 . The loss of SMEs' confidence in the economy which led them to decrease investments in fixed assets, thereby creating smaller pool of customers for the leasing providers to compete for. In addition, the dependence of the financial institutions' survivals are dependent on the interest income generated through financing products, it is important to understand the perceived service quality determinants by customers. Therefore, if leasing companies are to be profitable and successful, they need to understand the role of service quality and understand its impact on customer satisfaction and other behavioural outcomes.

\subsection{Defining Service Quality in Financial Sector}

Financial sector is one of the most institutionalised industries in the world due to the role that it plays in the economy. Hence, banks and financial institutions are highly regulated irrespective of where they are operating. Their performance depend on the economic welfare and trust of the public (Win, 2017). However, the 2008 financial crisis has caused the general public to lose their confidence in the financial system. Prior to the crisis, the financial sector in the developed countries were deregulated under neoliberalist economic philosophy. This gave financial institutions more leverage in terms of the types of additional services they provide consumers to establish their competitive advantage. The post crisis period led these institutions to operate in highly regulated environment which promotes stability over growth. This means they are competing in a restricted regulatory environment with limited public confidence in them. Therefore, understanding the impact of different dimensions of service quality on consumers become important for financial institutions' survival.

Services, in general, due to its lack of tangible attributes, customers are not able to ascertain the quality of a service prior to consumption and purchase. This makes the customer dependent on other signs of quality, like word of mouth or the reputation of the company, which increases the pressure on service provider to deliver what was promised (Haywood-Farmer, 1988). This is aggravated by the fact that inseparability of production and consumption of services and high involvement of the customer in the delivery process makes it almost impossible to hide quality shortfalls (Ghobadian et al., 1994). These characteristics and attributes of services are complicating a uniform definition of service quality. Ghobadian et al. (1994) identified five generic categories of definitions, clustered by the main drivers of quality: Transcendent, product led, process or supply led, customer led and value led. "Satisfying customer's requirements", as the definition of the costumer led approach and "meeting the customer's requirements in terms of quality, price, and availability", as the definition of the value led approach, are the most suitable to define service quality in order to measure the achievement of objects. Collart (2000) revised the idea of the value led approach of Ghobadian et al. (1994) and determined customer's perception of resulting service quality as one of the most important factors in a company's success. The perceived value of the service is seen as the determinant 
of customer satisfaction. Kumar et al. (2010) identified the performance of the service provider as the primary source of value creation. Service quality consists of two dimensions. The first dimension addresses the issue of what the service delivers and is referred to as "outcome quality" (Zeithaml et al., 1996). Grönroos (1984) coined the expression "technical quality" for the second dimension, which describes how the service is delivered. Both dimensions are following the approach that customer's judge service quality according to their personal perceptions. An assessment of perceived quality through the customer is only possible in the time period during or after a service is performed (Paswan et al., 2004). More precisely, "outcome quality" is evaluated after the service and "technical quality" is evaluated during the service is performed.

Service itself can be differentiated from material products with five characteristics namely intangibility, inseparability of provision from consumption, variability, perishability and absence of ownership. It is characterized by its complex nature which results from its common attributes intangibility, heterogeneity, high customer involvement, simultaneous production and consumption as well as perishability (Heizer and Render, 2011). In addition to these characteristics, financial services also possess two other important traits which are fiduciary responsibility and a two-way information flow (McKechnie, 1992). This is because financial services are provided customers over a long period of time. As mentioned by Zeithaml (2000), studying behavioural responses of customers to service quality can assist managers in estimating the financial outcomes of investing in service quality For example, once a customer opens a bank account, most of their financial transactions for a significant period of time will be done through the bank. This means banks can benefit from long term revenue generations from different financial products. Thus, in order to yield from long term benefits, financial service providers must understand customers' perceptions of service quality.

Despite the importance of service quality on financial institutions' survivals and profitability, prior literature studied service quality of banking services in general. It is true that banking services require a high degree of customer involvement and interactions with employees (Ozretic-Dosen and Zizak, 2015). However, the levels of interactions between customers and banks for different banking services are different, so are the level of service quality expected by the customers from banks. Banking services can be broadly differentiated into two forms, transaction support service and financial support-service. The former includes mobile banking, internet banking and Automated Teller Machine (ATM) where customers would use basic banking services such as checking balance and withdrawing cash. The transaction costs for banks in these services are significantly lower due to the limited direct interactions that banks have with their customers. On the other hand, financial support-services include loans, mortgage and lease applications. The providers have to incur high operational costs, investments and require a high degree of customer and bank interactions. They are also financial institutions' important revenue generation division. Therefore, prior literature has not taken into account of the importance of service quality importance on different banking services. In other words, their findings cannot be applied to all forms of financial services. 


\subsection{SERVQUAL Model and its Role in Measuring Service Quality in Financial Sector}

SERVQUAL instrument is first authored by Parasuraman et al. (1988) as a reliable tool to measure the quality of services from customer perspectives. Prior to this, Grönroos (1984) developed his perceived service quality model by combining technical and functional quality and including company reputation (image) as third component. He based his measurement model on the gap between customer expectations (pre-performance) and their experience during and after the performance (post-performance). However, it is not always possible for the customer to evaluate the technical quality of a service. For example in health care, the customer (patient) may have difficulties to assess the technical competence of the service provider or the results of the treatment. In this case, the customer has to rely on functional quality attributes to assess the delivered service (Kang and James, 2004). Focusing on these functional attributes of quality, Parasuraman et al. (1985) developed the GAP model. This model implicates that quality is a function of differences between expectations and performance and is based on the analysis of five gaps:

Gap1: customer expectation - management perception gap

Gap2: management perception - service quality specification gap

Gap3: service quality specification - service delivery gap

Gap4: service delivery - external communication gap

Gap5: expected service - perceived service gap

Parasuraman et al.(1988) introduced the SERVQUAL scale, which enabled them to ascertain customer expectations and perception and measure the gap between those attributes. In the same year, Haywood-Farmer (1988) stated that service can be divided into three groups of general attributes: physical facilities and processes, people's behaviour, and professional judgment. This division and the diversification of the three attributes into several factors build the general basis for his attribute service quality model. The synthesised model of service quality tries to address the issue of how customer expectations are raised. The model integrates external influences, like word of mouth, company reputation and marketing activities in the measurement process of customer expectations and investigates their impact. This model reseized the external communication part of Parasuraman's GAP model (Gap 4) (Brogowicz et al., 1990). Based on these models various approaches have been developed to appropriately measure service quality: the performance only model (Cronin and Taylor, 1992); Dabholkar and Bagozzi (2002) attribute and overall affect models; Service quality, customer value and customer satisfaction model (Oh, 1999); the internal service quality model (INTERSERVQUAL) (Frost and Kumar, 2000); the Internet banking model (Broderick and Vachirapornpuk, 2002) and the IT-based model (Zhu et al., 2002). From the above literature, it is clearly evident that the service quality can be measured as the gap between preperformance expectations and post-performance perception of customers. The SERVQUAL model, developed by Parasuraman et al. $(1985 ; 1988)$ is the most widely used model to measure expectations and perceived service quality (Angur et al., 1999).

Initially, Parasuraman et al. (1985) identified 97 attributes, which have a direct impact on service quality. These attributes had been classified into ten dimensions of service quality. Due to an overlap in the criteria of the dimensions, the authors condensed the ten into five 
dimensions. These five dimensions are: tangibility, reliability, responsiveness, assurance, and empathy. Tangibility includes the appearance of physical facilities, visible equipment, staff and printed materials. Reliability concerns the personnel's ability to accurately and professionally perform the service. Responsiveness is about the employee's willingness to perform the prompt service and help the customer. Assurance is the dimension that emphasizes on the know-how and knowledge of the employees and their ability to provide the costumer with a feeling of trust and confidence in the service provider. Caring, individual attention and appreciation of the customer are under the last dimension empathy. Customers' expectations and perceptions of the particular attribute are measured separately in a two column scale. Parasuraman et al. (1994) reduced the total number of items and formed the 22 item scale of the traditional SERVQUAL model. The 22-item scale was often extended or reduced, in order to tailor the model to a specific service sector (Buttle, 1996). Since then, it has been applied, developed and enhanced to measure service quality in different industries including financial service sector.

Avkiran (1994) applied SERVQUAL to Australian retail banking industry. The author developed a 17-item, four-factor scale to measure service quality. Aldlaigan and Buttle (2002) introduced the SYSTRA-SQ model. Wang et al. (2003) argued that in the banking industry, the purchasing and repurchasing behaviour of costumers are correlated to the reputation of the financial service provider. Arasil et al (2005) focused on Greek Cypriot banks revealed that the customer satisfaction level is heavily dependent on the people who deliver the service. Newman and Cowling (1996) used extended SERVQUAL model to compare two British banks. Koushiki (2013) investigated the influence of service quality on customers' purchase intentions in the Indian banking sector. In the study, he used 15-item scale to measure service quality. He found that there was strong support for the predictive power of perceived service quality on customers' purchase intentions and showed that reliability was the most important for influencing customers' purchase intentions, followed by employee behaviour, tangibles and convenience. Ozretic-Dosen and Zizak (2015) used SERVQUAL measurement to examine the quality of banking services among student population in Croatia. The results showed that there was a need to a gap in the quality of the banking services on all five dimensions of the SERVQUAL model, particularly in the areas of reliability, assurance and responsiveness, in which the gap was observed to be the largest. Indeed, there are other studies which have adopted SERVQUAL model to study service quality of banking sector in both emerging and developed markets (Cui et al., 2003; Zhou, 2004; Ladhari, 2009). However, it is not without criticisms.

SERVQUAL method has been criticised for its universality of the five dimensions across different cultures and ethnicities (Furrer et al., 2000). Some criticised that if expectations are measured after the service was performed, they could be biased by the actual perceived service quality (Teas, 1993). Amidst these criticisms, the SERVQUAL model, the most widely used service quality measurement tool, has been extended and modified since its development and is still used in service quality research. It is often used to assess the service quality in traditional service industries like hospitality and catering (Lee and Hing, 1995) but also in other industries like consumer retail environment, accounting firms, real estate, hospitals and travel agencies. The model, based on Grönroos (1984) model of technical and functional service quality, 
consists of service system, behavioural service, service transactional accuracy and machine service as dimensions of service quality measurement (Yavas et al., 2004).

Nevertheless, mere measurement of service quality is not able to create an added value for companies. It is by far more important to understand the relationship between the measured service quality, customer satisfaction and the consequent behavioural outcome. The linkages between service quality and a desired customer behaviours, like customer satisfaction, loyalty and willingness to recommend the company to others, have been studied for more than twenty years by various researchers (Zeithaml, 2000; Lee and Hwan, 2005). Simultaneously to the development of the synthesised model of service quality by Brogowicz et al. (1990) and Horovitz (1991) persued the same idea. They argued that the willingness to purchase of existing, as well as of potential customers, would be influenced by service quality. They justified their argument by the finding that a dis-satisfied customer would share his/her negative experience with more than three other persons. This implicates the conclusion that the dissatisfaction of customers, caused by poor service quality, not only decreases customer loyalty but also decreases the base of potential customers (Ghobadian et al., 1994).The described effect is intensified by the research findings of Smith and Lewis (1989). According to their study, the expectations of customers towards services are constantly rising, while at the same time their willingness to tolerate poor service quality is decreasing (Ramanathan and Ramanathan, 2011). These effects increased the likelihood of customers switching to a competitor dramatically. By implication, positive word of mouth, reached by high service quality and customer satisfaction, can be used as powerful marketing tool.

Yavas et al (2004) concluded that service quality is of key importance for customer satisfaction and the desired behavioural outcome such as word of mouth, recommending and switching. However, they qualified the statement considering that different aspects of service quality and different costumer characteristics can lead to different outcome. Veloutsou et al. (2004) also identified a strong linkage between perceived or experienced service quality and customer satisfaction, company reputation, brand commitment and customer loyalty. Their finding implicated that there is an increasing interest in the financial service sector in emphasizing on service quality, not only driven by the pressure to reduce cost but also because of the links between service quality, customer satisfaction and profitability (Lee and Hwan, 2005).

\subsection{Research Objectives}

In summary, authors have recognised the importance of service quality on customer purchase intentions of banking and financial services. However, these concepts are broadly defined. It is important to recognise different forms of services because not all of the services are created equally to meet diverse customer needs, hence, their expectations of service quality will be different from one service to another. In marketing literature, scholars implicitly define banking services as transaction support services. Due to technology innovations, financial service marketing scholars have studied customer adoptability of mobile banking and internet banking (Kim et al., 2010; Schierz et al., 2010). It shows that scholars have recognised the need to understand specific financial service segments. Nevertheless, they unintentionally disregarded financing services such as providing loans and leases though banks' main revenue generations come from these services. This service segment has been studied by banking and finance scholars. They investigate the influences of social, environmental and regulatory influences on 
providing loans and leases by financial institutions (Dietsch and Petey, 2002; Berger and Frame, 2005; Larson, 2013; Win, 2017). These differences occur because marketing scholars give more weighting on the role of customers when studying banks' transaction support services while the banking and finance scholars have assumed the power of banks in providing financing services. Therefore, the generalisability of prior studies on different forms of financial services become problematic.

Furthermore, in recent years, new institutions which provide financial services emerge, for example, leasing companies and building societies. Customers now have access to different asset financing options such as crowdfunding platforms and online lending. In such a competitive market environment, the balance of power has shifted from financial institutions to customers. Hence, there is a need to bridge this literature gap by differentiating financial services, and the customer expectations and their purchase intentions on diverse forms of services. This means customer expectations can be different from non-bank institutions and is important to recognise this gap. Especially in Germany, where the leasing sector plays a major role in asset financing appears to be a lack of research in the area of service quality and customer satisfaction measurement (BdL, 2011).

The gap analysis is widely accepted as measurement tool of service quality in the banking industry (Ladhari, 2009; Ozretic-Dosen and Zizak, 2015). In this paper, the SERVQUAL model is adapted to the leasing industry and more importantly test the applicability of model on measuring service quality on cusomter purchase intentions of financial support services. We take a step further by recognising the possible differences in private and corporate customers, and those business dealings with low, medium and high lease values. This is important because different types of customers will have specific demands due to their knowledge and educational backgrounds related to financial contracts and their acceptibility levels of exposures to financial risks. Furthermore, lease contract values also are important for leasing companies because of the transaction costs associated with them. High valued leased contracts and corporate customers are seens as favourable by leasers because they provide higher yields on investments due to lower operational costs resulting from lower asymmetry of information and processing costs. Therefore, if we can understand the most important SERVQUAL dimensions for these customers, leasing companies can reduce their operational costs and improve their profitability by targeting them effectively.

Hence, the collected data are used to answer the following questions:

Q1: Which are the most important SERVQUAL dimensions in the leasing sector?

Q2: Does the importance of the SERVQUAL dimensions differ between private (B to C) and corporate customers (B to B)?

Q3: Does the importance of the SERVQUAL dimensions differ between low, medium and high leasing value customers?

\section{Research method and data description}

\subsection{Questionnaire Design}

We use deduction method to test the service quality in a new industry and the relationship between customer satisfaction and desired behavioural outcomes. Robson (2002) argued that 
the approach of deduction can be realized the best by testing hypothesis through quantitative data collection and analysis. We used a highly structured systematic SERVQUAL questionnaire to ensure reliability. The developed questionnaire is based on the 22 item scale of the SERVQUAL approach but was modified to a 20 item scale. This was done because they were repetitive and difficult to comprehend by respondents in the first stage of the study.

The self-administrated questionnaire consists of three parts. Part one contains the 20 statements related to the dimensions of service quality. The participants were first asked to rate their expectations according to the importance of the statement on a Likert scale of 1 to 5 (1 - very low, 5 - very high). Then they were asked to assess the perceived service quality by rating the service they received. The second part of the questionnaire deals with the overall satisfaction and the behavioural outcome. The respondents were asked to rate their perception of the overall service quality, their willingness to continue the business relationship (retention), to recommend the company (word of mouth) and to consider the company as first choice (loyalty) on another 1 to 5 Likert scale. The last part contains questions about the socio-demographic profile and their leasing behaviour. In this part category questions are used where the respondent can choose his answer from a list of possibilities. These questions are used to differentiate the results between respondent groups like private and corporate customers. All questions used in the three parts of the survey are falling into the category of closed questions. This type of question is seen as advantages due to the minimisation of effort needed during answering and the simplicity in during the comparison of the results (Saunders et al., 2015).

The convenience sampling method, a technique of the non-probability sampling approach, has been used to carry out the questionnaires. This method has been widely used in business research such a market surveys (Saunders et al., 2015) and has been often used in the context of SERVQUAL analysis (e.g. Kumar et al., 2010). Nunnally (1978) recommended to adopt the sample size to the number of variable involved in the study. However, in social science literature, there is no consensus on the minimum sample size. For example, Hutcheson and Sofroniou (1999) recommended at least 150 cases while Hatcher and O'Rourke (2013) stated that to obtain reliable results, the minimal number of participants providing usable data for the analysis should be larger than 100 or 5 times the number of variables analysed. previously mentioned that subjects to variables ratio should not be less than 5 . As the questionnaire used in this research contains 20 variables of service quality, the recommended sampling size could range from 100 to 200. A lager sampling size could be possible but, considering the constraints of time and financial resources, we primarily aimed for sampling size of 200 . They were handed out or sent via e-mails to leasing customers that agreed to participate. Finally, 136 questionnaires were returned within the determined timeframe of four weeks. We obtained the response rate of $68 \%$, which was lower than expected. Due to missing data and incorrect use of the rating scales, six questionnaires had been rejected and restricted the final valid sample size to 130 . Nevertheless, the sample was within the targeted range of 100 to 200 .

\subsection{Method of analysis}

To analyse the data gathered from the primary research, SPSS for Windows ${ }^{\mathrm{TM}}$ has been used. To appropriately use SPSS to analyse the gathered data, all returned questionnaires have been 
checked and prepared. All of the data collected was categorised as categorical data. The questions asked in part one and two of the questionnaires have provided ranked data, which can be analysed in the same way as numerical interval data according to Cooper and Schindler (2016). Through the numerical interval analysis, it is possible to compare the results of customer expectations with the customer perception of the provided service quality and to evaluate their difference (gap) (Saunders et al., 2015).To make the data countable, the response categories have been pre-coded in a consecutive numbering for each question (e.g. private customer $=1$ and corporate customer $=2$ ). Initially, a comprehensive validity test is needed to ensure compliance with the recommendations of three types of validity (Cooper and Schindler, 2016). Content validity is concerned with the question, to which extend the chosen measurement device is able cover the investigative intention of the research. In this specific case: Is the used SERVQUAL approach able to measure service quality and customer satisfaction in the leasing industry? Construct validity covers the question, whether the measurement method used is able to measure the presence of the constructs they are intended to measure. In the case of SERVQUAL: Is this the measurement model of SERVQUAL generally able to measure the quality of services?

Cooper and Schindler (2016) recommend an evaluation of related literature and a comparison of similar studies to determine content and construct validity. Criterion-related validity is concerned the specific measures ability to accurately predict relationships between variables. In the case of this survey, it must be tested, if the questions concerning customer expectations and perception of service quality are able to predict customer satisfaction and desired behavioural outcome. The criterion-related validity test has been carried out according to the recommendations of Lam (1995). The measurements of expectations and perception of the five SERVQUAL dimensions have been tested on their correlations with the overall service quality and the three behavioural outcomes (continuation of the business relationship, willingness to recommend the company to others and consideration of the company as customer's first choice). According to Lam (1995), evidence of correlation between these variables proves criterion-related validity of the SERVQUAL model. Secondly, the reliability of the data has been verified mathematically by a formula of the internal consistency method, Cronbach's alpha. This method is recognised as the most widely used measurement of internal consistency. A value of 0.7 or higher represents an acceptable internal consistency and the data can be considered as reliable (Nunnally, 1978).

To ensure a preliminary prediction of the internal, content and criterion-related validity of the SERVQUAL model, a correlation analysis was conducted (Sureshchandar et al., 2002). Descriptive statistics have been used to measure the means and the standard deviation of the 20 items concerning the five SERVQUAL dimensions of service quality. The values of the expected means have been used to evaluate a ranking of the dimensions according to the expectations of customer. The idea behind this evaluation was, to find out on which dimensions the customer place the greatest value on. To underpin the importance of these dimensions, a regression analysis has been made. With the regression analysis, the tendency (positive or negative) and strength of a potential impact on the overall service quality has been assessed (Saunders et al., 2015). This analysis, in combination with the correlation analysis made to prove validity of the research questions. First, the evidence of correlation has been determined 
through the correlation coefficient. Subsequently, the tendency and strength of the impact on the dependent variable has been assessed. As recommended for the comparison of numerical data, Pearson's product moment correlation coefficient (PMCC) has been used (Saunders et al., 2015). To determine the cause-and-effect relationship between the SERVQUAL dimensions and the customer satisfaction (perceived overall service quality), a multiple regression analysis has been used. To test the four hypotheses, the normal regression analysis has been conducted.

\subsection{Sample Characteristics}

Due to the fact that the convenience sampling method was used, an analysis of the sociodemographical characteristics of the respondents was done to make prediction about their representativeness and the possibility of generalisation of the research findings. The sociodemographical findings are presented and discussed in the order they had been questioned. 106 of the 130 respondents are male and 24 are female. The average age of the participants is located in the age group of 45-54 years. $9 \%$ of the respondents are between 25 and 34, 26\% are between 35 and 44, 34\% are between 45 and 54, 30\% are between 55 and 64 and finally $1 \%$ is 65 or more. With a total number of 90 , the rate of corporate customers has reached $69 \%$. The ratio of private customers is $31 \%$ and 40 in total numbers.

According to the evaluation of customer groups in the German leasing sector, private households only contribute $15 \%$ to the total turnover (BdL, 2011). This suggests the assumption that private customers are overrepresented in this study. This issue will be addressed in research question number two (Q2) by evaluating possible differences between private and corporate customers concerning their perception of importance of the SERVQUAL dimension. The average volume of leasing investments the respondents are transacting totals between 100.000 and 500.000 euros per year.

\section{Analysis of results and discussions}

The content and construct validity of a research model like SERVQUAL is determined by the question whether the model is able to generally measure the components of service quality and whether it is appropriate in the specific environment of the conducted study. As shown in the literature review, it was widely agreed by researchers that measuring service quality as the gap between expectations and perceptions of customers. The SERVQUAL measurement, based on the GAP model, has been frequently used on behalf of the intention to measure service quality. Furthermore, in the field of assessing service quality and evaluating the relationship between service quality, customer satisfaction and behavioural outcome, the SERVQUAL approach has been predominantly used. Additionally, the model has been effectively deployed in various industries. Since the mid-nineties, SERVQUAL has been successfully adapted to the banking and financial service industry. In this paper, similar to previous researchers, a criterion-related validity test is conducted to prove the validity of SERVQUAL in the business environment of the leasing sector in Germany. 


\subsection{Validity and reliability analysis}

We have tried to reduce the number of items to analyse through factor analysis. Principal component analysis and confirmatory factor analysis have confirmed the existence of five SERVQUAL dimensions to measure overall service quality (see Table 3). Each of these dimensions has four elements with factor loadings above 0.4. Furthermore, we have conducted correlation analysis among SERVQUAL dimensions, customer satisfaction and behavioural outcome measures (recommend, continue business and first choice). The results of the correlation analysis for expected and perceived data are shown in Table 1. While most of SERVQUAL measures are significantly correlated to every other, no significant correlation exists between attractiveness and any other SERVQUAL measures. Similarly, correlation between attractiveness and other dimensions such as overall satisfaction, business continuation, recommend and first choice are also not significant. In customers' expectation, business continuation is significantly correlated to recommend and first choice. However, it is not correlated to any of SERVQUAL measures.

It can be seen that the overall service quality is significantly correlated with most of the dimensions of perceived service quality. The dimensions reliability, responsiveness and assurance show significant correlations, whereas attractiveness of the tangible assets and empathy of the employees show no significance. A similar effect can be noticed between the correlations of the perceptions of service quality dimensions and the three behavioural outcomes. These results imply that at least three strongly correlated dimensions are the key determinants of customer satisfaction and behavioural outcome. Further, it is worth mentioning that the correlations between expectations, customer satisfaction and the behavioural outcomes show less significance that with the perceived data. This suggests the assumption that expectations by themselves are not determining service quality or behavioural outcome. This is similar to the argument of Cronin and Taylor (1992). 
Table 1: Correlations

\begin{tabular}{|c|c|c|c|c|c|c|c|c|c|c|}
\hline & & \multicolumn{9}{|c|}{ Correlations - customers expectations } \\
\hline & & $\begin{array}{c}\text { Overall } \\
\text { satisfactio } \\
n\end{array}$ & $\begin{array}{l}\text { Continue } \\
\text { Business }\end{array}$ & $\begin{array}{c}\text { Recommen } \\
\mathrm{d}\end{array}$ & $\begin{array}{c}\text { First } \\
\text { Choice }\end{array}$ & Attractive & Reliability & $\begin{array}{c}\text { Responsive- } \\
\text { ness }\end{array}$ & Assurance & Empathy \\
\hline \multirow{9}{*}{ 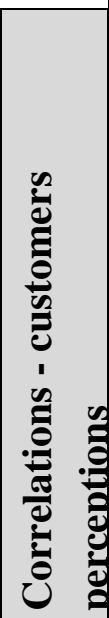 } & $\begin{array}{l}\text { Overall } \\
\text { satisfaction }\end{array}$ & 1 & $.777^{* *}$ & $.579^{* *}$ & $.564^{* *}$ & -0.118 & $.214^{*}$ & $.265^{* *}$ & $.528^{* *}$ & 0.129 \\
\hline & $\begin{array}{l}\text { Continue } \\
\text { Business }\end{array}$ & $.777^{* *}$ & 1 & $.932^{* * *}$ & $.891^{* *}$ & -0.099 & 0.089 & -0.074 & 0.125 & -0.032 \\
\hline & Recommend & $.579^{* *}$ & $.932^{* *}$ & 1 & $.954^{* *}$ & -0.044 & 0.038 & $-.188^{*}$ & -0.022 & -0.113 \\
\hline & First Choice & $.564^{* *}$ & $.891^{* *}$ & $.954^{* *}$ & 1 & -0.029 & 0.023 & -0.157 & -0.032 & -0.12 \\
\hline & Attractive & 0.034 & 0.011 & 0.017 & 0.06 & 1 & -0.053 & 0.115 & 0.051 & 0.04 \\
\hline & Reliability & $.203^{*}$ & 0.118 & 0.086 & 0.05 & 0.061 & 1 & $.306^{* *}$ & $.215^{*}$ & -0.026 \\
\hline & Responsiveness & $.471^{* *}$ & $.229^{* *}$ & 0.101 & 0.111 & 0.167 & $.313^{* *}$ & 1 & $.356^{* *}$ & $.224^{*}$ \\
\hline & Assurance & $.696^{* *}$ & $.414^{* *}$ & $0.271^{\text {*** }}$ & $.253^{* *}$ & 0.055 & $.200^{*}$ & $.377^{* *}$ & 1 & $.301^{* *}$ \\
\hline & Empathy & 0.096 & -0.051 & -0.105 & -0.102 & 0.089 & -0.037 & 0.168 & $.267^{* *}$ & 1 \\
\hline
\end{tabular}

**. Correlation is significant at the 0.01 level (2-tailed).

*. Correlation is significant at the 0.05 level (2-tailed). 
After verifying the validity of the SERVQUAL model, the reliability of the gathered data has been analysed (Saunders et al., 2015). Cronbach's alpha, the coefficient of internal consistency has been evaluated for the following data constellation: Overall reliability of data, data of expected service quality and data of perceived service quality. To prove the general reliability of the data collected, Cronbach's coefficient alpha has been calculated from expected and perceived data including the values of customer satisfaction and behavioural outcome. The coefficient alpha of the overall internal consistency is calculated as 0.85 . The fact that the calculated value exceeds 0.70 proves the reliability of the overall data. Then, we have checked the reliability of the data for corporate and private customers independently for both expected and perceived data. Both individual sets of data exceeded the benchmark of 0.70 on the coefficient alpha (see Tables $2 \mathrm{a}$ and $2 \mathrm{~b}$ ). Percentage of variance explained by all the six attributes namely overall satisfaction, attractiveness, reliability, responsiveness, assurance and empathy are above $38 \%$.

Table 2a: Internal consistencies (private/corporate data)

\begin{tabular}{|c|c|c|c|c|}
\cline { 2 - 5 } \multicolumn{1}{c|}{} & \multicolumn{2}{c|}{ Private customers } & \multicolumn{2}{c|}{ Corporate customers } \\
\cline { 2 - 5 } & $\begin{array}{c}\text { expected } \\
\text { data }\end{array}$ & $\begin{array}{c}\text { perceived } \\
\text { data }\end{array}$ & $\begin{array}{c}\text { expected } \\
\text { data }\end{array}$ & $\begin{array}{c}\text { perceived } \\
\text { data }\end{array}$ \\
\hline $\begin{array}{c}\text { Cronbach's } \\
\text { alpha }\end{array}$ & 0.716 & 0.711 & 0.706 & 0.701 \\
\hline
\end{tabular}

Table 2b: Internal consistencies (perceived data)

\begin{tabular}{|l|r|r|r|r|r|r|}
\hline & $\begin{array}{l}\text { Overall } \\
\text { service } \\
\text { quality }\end{array}$ & Attractiveness & Reliability & Responsiveness & Assurance & Empathy \\
\hline $\begin{array}{l}\text { Cronbach's } \\
\text { alpha }\end{array}$ & 0.846 & 0.715 & 0.819 & 0.753 & 0.842 & 0.882 \\
$\begin{array}{l}\text { Percentage of } \\
\text { variance }\end{array}$ & 95.06 & 67.0 & 45.01 & 38.24 & 48.94 & 56.39 \\
\hline
\end{tabular}

\subsection{Further Analysis}

Table 3 lists the results of descriptive statistical analysis of expectations of private and corporate customers. Means of the customers' expectation data show that three dimensions (namely reliability, responsiveness and assurance) of the SERVQUAL approach have the highest importance from a customer point of view. These are the same dimensions that had the most significant correlations with customer satisfaction and the behavioural outcome attributes. To underpin the importance of these dimensions, a regression analysis with the perceived data of the three dimensions has been conducted. 
Table 3: Descriptive Statistics - customer expectations

\begin{tabular}{|c|c|c|c|c|c|c|}
\hline & \multicolumn{2}{|c|}{$\begin{array}{c}\text { Private customer } \\
\text { expectation }(\mathrm{N}= \\
40)\end{array}$} & \multicolumn{2}{|c|}{$\begin{array}{c}\text { Corporate customer } \\
\text { expectation }(\mathrm{N}= \\
90)\end{array}$} & \multirow[b]{2}{*}{ 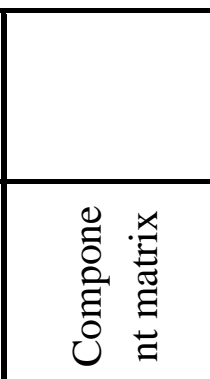 } & \multirow[b]{2}{*}{ 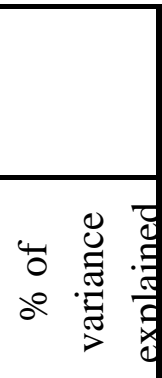 } \\
\hline & 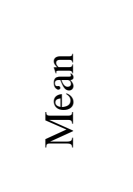 & 兽 & 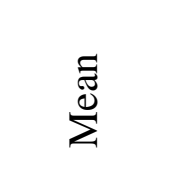 & i⿱宀 & & \\
\hline Attractive1 & 2.4750 & .84694 & 2.2778 & .86151 & .891 & \\
\hline Attractive2 & 2.6250 & .86787 & 2.5000 & .82448 & .670 & \\
\hline Attractive3 & 2.5500 & .84580 & 2.5222 & 1.06241 & .790 & \\
\hline Attractive4 & 2.6500 & .83359 & 2.7778 & .96893 & .411 & 47.74 \\
\hline Reliablity1 & 3.0000 & 67937 & 3.4222 & .84770 & .750 & \\
\hline Reliabilty2 & 2.8750 & .64798 & 3.3333 & .82107 & .713 & \\
\hline Reliabilty3 & 3.0250 & 69752 & 3.4333 & .79394 & .690 & \\
\hline Reliabilty4 & 3.1000 & .77790 & 3.3556 & .70808 & .634 & 48.76 \\
\hline Responsiveness 1 & 3.4250 & 63599 & 3.6222 & .77282 & .698 & \\
\hline Responsiveness 2 & 3.3750 & .80662 & 3.6000 & .74653 & 691 & \\
\hline Responsiveness 3 & 3.3750 & .77418 & 3.5889 & .70143 & .630 & \\
\hline Responsiveness4 & 3.4000 & .74421 & 3.5444 & .70569 & .509 & 40.51 \\
\hline Assurance1 & 3.3750 & .70484 & 3.6556 & .79551 & .716 & \\
\hline Assurance2 & 3.3250 & .94428 & 3.6000 & .79039 & .838 & \\
\hline Assurance3 & 3.2750 & .90547 & 3.5778 & .80696 & .759 & \\
\hline Assurance4 & 3.2750 & .81610 & 3.6000 & .79039 & .563 & 52.68 \\
\hline Empathy1 & 3.0250 & 69752 & 3.1778 & .82894 & .628 & \\
\hline Empathy2 & 3.2500 & .92681 & 3.3000 & .86700 & .841 & \\
\hline Empathy3 & 3.3000 & .82275 & 3.2111 & .72661 & .710 & \\
\hline Empathy4 & 3.1500 & .80224 & 3.2222 & .83165 & .864 & 58.78 \\
\hline Satisfaction & 3.2750 & 64001 & 3.2000 & .67375 & & \\
\hline ContinueBusiness & 3.1250 & .79057 & 2.7778 & 1.04696 & & \\
\hline Recommend & 3.0000 & 1.08604 & 2.5778 & 1.23596 & & \\
\hline FirstChoice & 3.0000 & 1.08604 & 2.5889 & 1.21687 & & \\
\hline Valid N (listwise) & $\begin{array}{r}(\mathrm{N}= \\
40)\end{array}$ & & $(\mathrm{N}=90)$ & & $(\mathrm{N}=130)$ & \\
\hline
\end{tabular}

Since all three dimensions of behavioural outcomes and customer satisfaction have positive correlations and also grouped as a single factor, we name these four elements as 'Overall service quality'. We have conducted regression analysis for private and corporate customers separately. For private customers' perceived data, regression analysis, with overall service quality as dependent variable and all the five dimensions of service quality as independent variables, shows a significant impact of responsiveness, assurance and empathy; while other 
dimensions namely attractiveness and reliability are not significant at $\mathrm{p}<0.05$ (see Table 4). Adjusted R-square of this model is 0.79 . These results implicate that responsiveness, assurance and empathy have significant positive impacts on customer satisfaction, while reliability has no significance for private customers. Similar analysis has been conducted with corporate customers' perceived data. The result of the regression shows that the overall service quality perceived by corporate customers is significantly related to the responsiveness and assurance of the company (see Table 5).

Table 4: Regression - private customers' perception data

Coefficients $^{\mathrm{a}}$

\begin{tabular}{|c|c|c|c|c|c|}
\hline \multirow[b]{2}{*}{ Model } & \multicolumn{2}{|c|}{$\begin{array}{c}\text { Unstandardized } \\
\text { Coefficients }\end{array}$} & \multirow{2}{*}{$\begin{array}{c}\begin{array}{c}\text { Standardized } \\
\text { Coefficients }\end{array} \\
\text { Beta }\end{array}$} & \multirow[b]{2}{*}{$\mathrm{t}$} & \multirow[b]{2}{*}{ Sig. } \\
\hline & B & Std. Error & & & \\
\hline (Constant) & -.301 & .441 & & -.683 & .499 \\
\hline Responsiveness & .125 & .031 & .372 & 4.086 & .000 \\
\hline Assurance & .210 & .024 & .826 & 8.654 & .000 \\
\hline Empathy & -.071 & .027 & -.269 & -2.671 & .011 \\
\hline
\end{tabular}

a. Dependent Variable: OverallServiceQuality

Table 5: Regression - corporate customers' perception data

\section{Coefficients $^{\mathrm{a}}$}

\begin{tabular}{|l|r|r|r|r|r|}
\hline \multirow{2}{*}{ Model } & \multicolumn{2}{|c|}{$\begin{array}{c}\text { Unstandardized } \\
\text { Coefficients }\end{array}$} & $\begin{array}{c}\text { Standardized } \\
\text { Coefficients }\end{array}$ & \multirow{2}{*}{ t } & \multicolumn{1}{c|}{ Sig. } \\
\cline { 2 - 5 } & \multicolumn{1}{|c|}{$\mathrm{B}$} & Std. Error & \multicolumn{1}{c|}{ Beta } & \multicolumn{1}{c|}{$\mathrm{t}$} \\
\hline (Constant) & -.278 & .450 & & -.617 & .539 \\
Responsiveness & .085 & .034 & .231 & 2.489 & .015 \\
Assurance & .183 & .027 & .588 & 6.793 & .000 \\
\hline
\end{tabular}

a. Dependent Variable: Overall service quality

For both the corporate and private customers, responsiveness and assurance are important significant factors of overall service quality. However, empathy is additional significant factor for private customers' perceived service quality. Negative coefficient of this dimension represents that the more the understanding of the product (especially the risk), the less the satisfaction. For both private and corporate customers attractiveness and reliability do not play a significant role in perceived overall service quality.

While some private customers have business dealing with the company for more than 0.5 million Euros, some corporate customers deal with the company for a low value of less than 0.25 million Euros. Hence, we have conducted regression analysis to identify the impact of SERVQUAL dimensions on overall service quality for different customers based on their business dealing of leasing value with the company. Accordingly, we have divided the 
perceived SERVQUAL data into three categories: low (less than 50,000 Euros), medium (50,000 - 500,000 Euros) and high (above 500,000 Euros). Regression results of these three groups show an interesting insight. Assurance is the common significant factor of overall service quality for all customers. However, empathy has significant negative impact on low and high value customers. Reliability is also one of the significant factors of deciding overall service quality in the perception of low value customers (see Table 6).

Table 6: Regression - Low, medium and high leasing values

\begin{tabular}{|c|c|c|c|c|c|}
\hline \multicolumn{6}{|c|}{ Coefficients $^{\mathbf{a}}$} \\
\hline \multirow{2}{*}{$\begin{array}{l}\text { Model - } \\
\text { Low } \\
\text { leasing } \\
\text { value (n= } \\
\text { 36) }\end{array}$} & \multicolumn{2}{|c|}{$\begin{array}{l}\text { Unstandardized } \\
\text { Coefficients }\end{array}$} & \multirow{2}{*}{$\begin{array}{c}\text { Standardi } \\
\text { zed } \\
\text { Coefficie } \\
\text { nts }\end{array}$} & \multirow[b]{2}{*}{$\mathrm{t}$} & \multirow[b]{2}{*}{ Sig. } \\
\hline & $\mathrm{B}$ & $\begin{array}{l}\text { Std. } \\
\text { Error }\end{array}$ & & & \\
\hline (Constant) & .383 & .105 & & 3.661 & .001 \\
\hline Assurance & .660 & .114 & .728 & 5.770 & .000 \\
\hline Empathy & -.423 & .108 & -.499 & -3.908 & .000 \\
\hline Reliability & .346 & .124 & .318 & 2.799 & .008 \\
\hline \multicolumn{6}{|c|}{ Model - Medium leasing value $(n=50)$} \\
\hline (Constant) & -.109 & .134 & & -.812 & .421 \\
\hline Assurance & .333 & .126 & .356 & 2.637 & .011 \\
\hline \multicolumn{6}{|c|}{ Model - High leasing value $(n=44)$} \\
\hline (Constant) & -.309 & .140 & & -2.208 & .034 \\
\hline Assurance & .568 & .156 & .496 & 3.647 & .001 \\
\hline Empathy & -.429 & .156 & -.373 & -2.741 & .010 \\
\hline
\end{tabular}

\section{Conclusions and Implications}

\section{Summary of Conclusions}

This study has examined the psychometric factors of SERVQUAL on leasing market in Germany. Primarily, we intended to assess the validity of the model in the German leasing market and to test the existing research in a new business context. It is validated after using recommended procedures outlined by Parasuraman et al. (1988). In order to answer research questions outlined in section 2.3, we identified the determinants of overall service quality (i.e. customer satisfaction and desired behavioural outcomes). In order to measure and assess these determinants and relationships, widely recommended statistical analyses have been used. The differentiation between the two customer groups has been undertaken to provide appropriate finding for leasing companies. This is important to understand as they serve both private and corporate customers. We hypothesised that their determinants of service quality would be different. The findings from description and regression analyses are shown in Table 4 and Table 5 . 
As we expected, we found differences in the levels of SERVQUAL dimensions on corporate and private customers. According to our analyses, 'Responsiveness' and 'assurance' of the leasing company have significant impact on corporate customers' perception of overall service quality. On the other hand, regression results of the private customer perceptions identified significant impacts of three dimensions of SERVQUAL namely 'responsiveness', 'assurance' and 'empathy' on the overall service quality. This suggests that private customers place more value on 'empathy' than corporate customers. The issues related to employees giving attention and understanding of the clients' needs weighted more on private customers. This might be because private customers are more likely to have limited knowledge of leasing terms and condition as opposed to corporate customers when applied for asset financing. This may also be due to the fact that the private customers take the risk of dealing with the company for their personal and commercial reasons independently. Hence, they would require more attentiveness and understanding from employees. This imply that private customers are more likely to lease from companies which can demonstrate empathy.

From the regression analysis based on three different leasing value customers, it is clear that 'assurance' from the leasing company is the most common SERVQUAL dimension that has significant impact on overall service quality perceptions of the customers. This finding contradicts with Ozretic-Dosen and Zizak (2015) who found that 'reliability', i.e. the ability of the financial service company to perform services on time and without error. 'Assurance' is related to the clarity of information, employees possessing necessary information on demand and the levels of employees' competence in preventing customers from exposing to security and financial risks, thereby instilling confidence in them. This could be because the customers in the sample are dealing with financing and financial resources rather than normal day to day banking transactions which are inherently risk-free. While 'empathy' is significant for low and high value customers, 'reliability' has significant role only for low value customers. This answers our third research question that the impact of SERVQUAL dimensions in overall service quality differ in the perception of low, medium and high leasing value customers.

Results of descriptive statistics and regression analysis clearly specify the importance of SERVQUAL dimensions in obtaining customers satisfaction and loyalty (behavioural outcomes). Except 'attractiveness', all the other SERVQUAL dimension play a vital role in obtaining satisfaction of the customers. This finding is similar to previous studies which employed variants of SERVQUAL models in financial service industries (Cui et al., 2003; Zhou, 2004; Koushiki, 2013; Ozretic-Dosen and Zizak, 2015). It could be argued that tangibles, in contrast to other service sectors like hospitality or gastronomy, are not as important in the leasing sector than initially assumed. Expensive equipment and fashionable designed buildings could be mistaken as unnecessary status symbols or sheer boast in the perception of the customers. Unlike all the previous studies, we found that 'empathy' has negative impact on customers' satisfaction. This is mainly because the ability of employees to provide customers with detailed understanding of rules and regulations in leasing would reveals any hidden risks such as repossession conditions and repayment terms agreements in contracting process. This could improve the ability of the customers to make more informed decisions for themselves. This reduced level of satisfaction results in negative impact on recommending to friends or considering the company as customers' first choice or continuing business. Our results are 
different from Lassar et al. (2000), who identified 'attractiveness' and 'empathy' as main drivers of service quality and customers' satisfaction in private banking. This could be contributed to the effects of financial instability after 2008 which led the customers to be more concerned about transparency of information before signing financing contracts with leasing companies rather than focusing on the tangibles.

In the data analysis, a significant positive correlation between customer satisfaction and the three behavioural outcomes has been revealed. This finding implies that customer satisfaction determines the future behaviour of the customer. If a customer is satisfied with the service he/she perceived, the likelihood of switching of decrease, while his willingness to recommend to company and his loyalty will increase. Our results support the findings of Yavas et al. (2004) in the private banking sector of Germany. These evaluations, compared with the conclusion of the key determinants of service quality, stated above, permit the following inference. If behavioural outcome is determined by customer satisfaction and customer satisfaction is dependent on the SERVQUAL dimensions responsiveness and assurance, then the two dimensions have an indirect impact on the behavioural outcome of customers. However, to reveal a direct linkage between the service dimensions and the behavioural outcome, further research has to be conducted. It should be evaluated which dimension has the most significant impact on which kind of desired behaviour.

\section{Implications}

This research has both theoretical and practical implications. From theoretical perspectives, by recognising the complex nature of financial services, we validated the applicability of SERVQUAL model on leasing market in Germany. Prior studies have defined financial and banking services as a simple concepts as all of these services have equally distributed importance for customers and investments. They have not recognised that not all these services are created equally to meet customer demands. Hence, the customer expectations of service quality are different. We also contributed to the marketing literature by studying customer perceptions of service quality by specifying financing aspects of financial services, i.e. leasing. We further contributed to the literature of SERVQUAL model in financial services by dividing customers into two categories: corporate and private. We also divided the values of leasing contracts into low, medium and high valued contracts. We found that priorities given on service quality dimensions by them are different. These concepts were never considered in the literature. Hence, our findings are comparable to other studies at aggregate level. This also implies that future studies on financial services marketing need to recognise such differences in the research.

Given the competition in the financial service sector, the institutions should be aware the impact of different dimensions of service quality on diverse services that they offer. This can increase their profitability through retaining existing customers and attracting new ones. The leasing firms or financial institutions that provide leasing services can also benefit from focusing their operational costs on improving certain dimensions of service quality on different types of customers. In this case, leasing companies should focus their efforts on the 'responsiveness' and 'assurance' dimensions for corporate customers and 'empathy' for private 
customers. These costs could arise from providing adequate training for staff by focusing to improve these dimensions for increased in customer satisfaction.

\section{Limitations and Future Work}

The paper has three limitations which are suggestive for future research. First, we used convenience sampling method to collection information from leasing customers who are conveniently available. This approach eases the procedure of information gathering but simultaneously precludes the findings to be extrapolated to the population of the investigated target group. Secondly, to enable a generalisation of the research findings, a survey with larger sample should be conducted in this business context. Thirdly, we did not specify the leasing companies into manufacturer and third party leasing. There is a possibility that customer expectations of service quality would be different from how they would like to finance their assets. Hence, further adaptation measures of the SERVQUAL scale should be taken to completely determine the drivers of service quality in the different characteristics of German leasing market. Considering the research limitations, the conclusions of this study cannot be generalised for the entire leasing market of Germany. However, our research can be used as an initial step towards further examination of service quality in leasing market.

\section{References}

ALDLAIGAN, A. H. \& BUTTLE, F. A. 2002. SYSTRA-SQ: a new measure of bank service quality. International Journal of Service Industry Management, 13, 362-381.

AVKIRAN, N. K. 1994. Developing an Instrument to Measure Customer Service Quality in Branch Banking. International Journal of Bank Marketing, 12, 10-18.

BDL, B. D. L. U. 2011. Year-on-Year Data and Data Relating to Leasing Structures [Online]. Available: http://www.bdl-leasing-verband.de/ [Accessed 24/03/2011 2011].

BERGER, A. N. \& FRAME, W. S. 2005. Small Business Credit Scoring and Credit Availability. Atlanta.

BRODERICK, A. J. \& VACHIRAPORNPUK, S. 2002. Service quality in Internet banking: the importance of customer role. Marketing Intelligence \& Planning, 20, 327-335.

BROGOWICZ, A. A., DELENE, L. M. \& LYTH, D. M. 1990. A Synthesised Service Quality Model with Managerial Implications. International Journal of Service Industry Management, 1, 2745.

BUTTLE, F. 1996. SERVQUAL: review, critique, research agenda. European Journal of Marketing, 30, 8-32.

COLLART, D. 2000. Customer Relationship Management, New York, PriceWaterHouseCoopers.

COOPER, D. \& SCHINDLER, P. 2016. Business Research Methods, McGraw-Hill Higher Education - VST E+p.

CRONIN, J. J. \& TAYLOR, S. A. 1992. Measuring Service Quality: A Reexamination and Extension. Journal of Marketing, 56, 55-68.

CUI, C. C., LEWIS, B. R. \& PARK, W. 2003. Service quality measurement in the banking sector in South Korea. International Journal of Bank Marketing, 21, 191-201.

DABHOLKAR, P. A. \& BAGOZZI, R. P. 2002. An attitudinal model of technology-based self-service: Moderating effects of consumer traits and situational factors. Journal of the Academy of Marketing Science, 30, 184.

DIETSCH, M. \& PETEY, J. 2002. The credit risk in SME loans portfolios: Modeling issues, pricing, and capital requirements. Journal of Banking \& Finance, 26, 303-322.

EC, E. C. 2015. European Economy: Macroeconomic Imbalances Country Report - Germany 2015. Economic and Financial Affairs.

FROST, F. A. \& KUMAR, M. 2000. INTSERVQUAL - an internal adaptation of the GAP model in a large service organisation. Journal of Services Marketing, 14, 358-377. 
FURRER, O., LIU, B. S.-C. \& SUDHARSHAN, D. 2000. The Relationships between Culture and Service Quality Perceptions. Journal of Service Research, 2, 355-371.

GHOBADIAN, A., SPELlER, S. \& JONES, M. 1994. Service Quality: Concepts and Models. International Journal of Quality \& Reliability Management, 11, 43-66.

GLEESON, B. 2017. 2017 Global Leasing Report. White Clarke Group.

GRÖNROOS, C. 1984. A Service Quality Model and its Marketing Implications. European Journal of Marketing, 18, 36-44.

HATCHER, L. \& O'ROURKE, N. 2013. A Step-by-Step Approach to Using SAS for Factor Analysis and Structural Equation Modeling, SAS Institute.

HAYWOOD-FARMER, J. 1988. A Conceptual Model of Service Quality. International Journal of Operations \& Production Management, 8, 19-29.

HEIZER, J. \& RENDER, B. 2011. Operations management, Pearson.

HOROVITZ, J. 1991. How to Win Customers: Using Customer Service for a Competitive Edge, Financial Times Management

HUTCHESON, G. D. \& SOFRONIOU, N. 1999. The Multivariate Social Scientist: Introductory Statistics Using Generalized Linear Models, SAGE Publications.

KANG, G. D. \& JAMES, J. 2004. Service quality dimensions: an examination of Grönroos's service quality model. Managing Service Quality: An International Journal, 14, 266-277.

KIM, C., MIRUSMONONV, M. \& LEE, I. 2010. An empirical examination of factors influencing the intention to use mobile payment. Computers in Human Behaviour, 26, 310-22.

KOUSHIKI, C. 2013. Service quality and customers' purchase intentions: an empirical study of the Indian banking sector. International Journal of Bank Marketing, 31, 529-543.

KUMAR, M., KEE, F. T. \& CHARLES, V. 2010. Comparative evaluation of critical factors in delivering service quality of banks: An application of dominance analysis in modified SERVQUAL model. International Journal of Quality \& Reliability Management, 27, 351-377.

LADHARI, R. 2009. Assessment of the psychometric properties of SERVQUAL in the Canadian banking industry. Journal of Financial Services Marketing, 14.

LAM, S. S. K. 1995. Assessing the validity of SERVQUAL: an empirical analysis in Hong Kong. Asia Pacific Journal of Quality Management.

LARSON, E. 2013. Demand for credit, international financial legitimacy, and vulnerability to crises: Regulatory change and the social origins of Iceland's collapse. Regulation \& Governance, n/an/a.

LASSAR, W. M., MANOLIS, C. \& WINSOR, R. D. 2000. Service quality perspectives and satisfaction in private banking. Journal of Services Marketing, 14, 244-271.

LEASEUROPE 2015. The Voice of Leasing and Automative Rental in Europe. In: LEASEEUROPE (ed.).

LEE, M. C. \& HWAN, I. S. 2005. Relationships among Service Quality, Customer Satisfaction and Profitability in the Taiwanese Banking Industry. International Journal of Management, 22.

LEE, Y. L. \& HING, N. 1995. Measuring quality in restaurant operations: an application of the SERVQUAL instrument. International Journal of Hospitality Management, 14, 293-310.

MACCALLUM, R. C., WIDAMAN, K. F., ZHANG, S. \& S., H. 1999. Sample size in factor analysis. . Psychological Methods, 4, 84-99.

MCCONNELL, J. J. \& SCHALLHEIM, J. S. 1983. Valuation of asset leasing contracts. Journal of Financial Economics, 12, 237-261.

MCKECHNIE, S. 1992. Consumer Buying Behaviour in Financial Services: An Overview. International Journal of Bank Marketing, 10, 5-39.

NEWMAN, K. \& COWLING, A. 1996. Service quality in retail banking: the experience of two British clearing banks. International Journal of Bank Marketing, 14, 3-11.

NUNNALLY, J. C. 1978. Psychometric theory, McGraw-Hill.

OH, H. 1999. Service quality, customer satisfaction, and customer value: A holistic perspective. International Journal of Hospitality Management, 18, 67-82.

OZRETIC-DOSEN, D. \& ZIZAK, I. 2015. Measuring the quality of banking services targeting student population. EuroMed Journal of Business, 10, 98-117. 
PARASURAMAN, A., BERRY, L. \& ZEITHAML, V. 1994. Reassessment of expectations as a comparison standard in measuring SQ: implications for future research. Journal of Marketing, 58.

PARASURAMAN, A., ZEITHAML, V. \& BERRY, L. L. 1988. SERVQUAL: a multiple-item scale for measuring consumer perceptions of service quality. Journal of Retailing, 64.

PARASURAMAN, A., ZEITHAML, V. A. \& BERRY, L. L. 1985. A Conceptual Model of Service Quality and Its Implications for Future Research. Journal of Marketing, 49, 41-50.

PASWAN, A. K., SPEARS, N., HASTY, R. \& GANESH, G. 2004. Search quality in the financial services industry: a contingency perspective. Journal of Services Marketing, 18, 324-338.

RAMANATHAN, U. \& RAMANATHAN, R. 2011. Guests' perceptions on factors influencing customer loyalty: An analysis for UK hotels. International Journal of Contemporary Hospitality Management, 23, 7-25.

SAUNDERS, M. N. K., LEWIS, P. \& THORNHILL, A. 2015. Research Methods for Business Students, Pearson Education Limited.

SCHIERZ, P. G., SCHILKE, O. \& WIRTZ, B. W. 2010. Understanding consumer acceptance of mobile payment services: An empirical analysis. Electronic Commerce Research and Applications, 9, 209-216.

SMITH, A. M. \& LEWIS, B. R. 1989. Customer Care in Financial Service Organisations. International Journal of Bank Marketing, 7, 13-22.

SURESHCHANDAR, G. S., RAJENDRAN, C. \& ANANTHARAMAN, R. N. 2002. Determinants of customer-perceived service quality: a confirmatory factor analysis approach. Journal of Services Marketing, 16, 9-34.

TEAS, R. K. 1993. Expectations, Performance Evaluation, and Consumers' Perceptions of Quality. Journal of Marketing, 57, 18-34.

VELOUTSOU, C., GIOULISTANIS, E. \& MOUTINHO, L. 2004. Own labels choice criteria and perceived characteristics in Greece and Scotland: factors influencing the willingness to buy. Journal of Product \& Brand Management, 13, 228-241.

WANG, Y., HING-, P. L. \& YER, V. H. 2003. The antecedents of service quality and product quality and their influences on bank reputation: evidence from the banking industry in China. Managing Service Quality: An International Journal, 13, 72-83.

WIN, S. 2017. Banks' Lending Behaviour under Represed Financial Regulatory Environment: in the Context of Myanmar. Pacific Accounting Review, 29.

YAVAS, U., BENKENSTEIN, M. \& STUHLDREIER, U. 2004. Relationships between service quality and behavioral outcomes: A study of private bank customers in Germany. International Journal of Bank Marketing, 22, 144-157.

ZEITHAML, V. A. 2000. Service Quality, Profitability, and the Economic Worth of Customers: What We Know and What We Need to Learn. Journal of the Academy of Marketing Science, 28, $67-$ 85.

ZEITHAML, V. A., BERRY, L. L. \& PARASURAMAN, A. 1996. The Behavioral Consequences of Service Quality. Journal of Marketing, 60, 31-46.

ZHOU, L. 2004. A dimension-specific analysis of performance-only measurement of service quality and satisfaction in China's retail banking. Journal of Services Marketing, 18, 534-546.

ZHU, F. X., WYMER, W. \& CHEN, I. 2002. IT-based services and service quality in consumer banking. International Journal of Service Industry Management, 13, 69-90. 